\title{
REVEALING GHOST BUSINESS-TO-BUSINESS CLIENTS THROUGH GOSH'S MODEL. A CHALLENGE FOR EU LEISURE AND ENTERTAINMENT ACTIVITIES
}

\author{
Maurizio Droli \\ Ting Fa Margherita Chang \\ Luca Iseppi \\ Department of Civil Engineering and Architecture, \\ University of Udine, Italy
}

\begin{abstract}
The concept of intermediate market trade contacts (ITC) have been developed as transactional capital resource measured by business-to-business purchases or sales. In the framework of the resource-based view, only valuable, rare, inimitable and non-substitutable firm's resources might be considered as a source of sustained competitive advantage. Supplydriven Ghosh's model has been applied to Eurostat symmetric input-output tables of 23 EU countries. A strong and direct relationship between market horizontal multiplier for productive use and indirect ITC frequency has been found for recreational, cultural and sporting activities. Consequently, valuable and distinct hidden-client purchases could be used as a resource favoring firm development, innovation and territorial integration strategies.

Keywords: business-to-business market, competitive advantage, footholds, input-output analysis, integration, recreational, cultural and sporting activities, resource-based theory, trade contacts.
\end{abstract}

\section{Introduction $^{11}$}

"Recreational, cultural and sporting activities" (Recreationals) together with accommodation and food services firms constitute a significant part of tourism supply and create value to the broader socio-economic system. Despite this, not all the operators fully recognize the importance of relations created among the involved firms and other kind of businesses or public operators when it comes to define socio-economic integration strategies.

As resulted from the Eurostat Input-output tables (2012) in 2007 the 'Recreationals' produced in EU-27 countries an output and a value added of $€$ 390.9 and $€ 195.5$ billion (at basic prices), equivalent to $1.7 \%$ and $1.8 \%$ on the respective totals of the whole EU economy. On the purchase side, the businessto-business (B2B) sales of the 'Recreationals' achieved the relevant value of $€$ 187.9 billion. While, on the sale side they accounted for 127.9 billion. Standing alone, business-to-consumer (B2C) reached $€ 263.1$ billion. In the resourcebased view framework, only 'valuable', 'rare', 'inimitable' and 'nonsubstitutable' firm's resources may become a source of sustained competitive advantage (Barney, 1991).

\footnotetext{
${ }^{11}$ This section is common to the Authors.
} 
This study is intended to deal with methods and measurement issues in the framework of the Resource-based theory, using the potentialities offered by the highly standardized methodology of the input-output analysis (Droli et al. 2013). The broad main aim of this research is threefold: to advance few R-BV keyconcepts; ii) to describe and discuss the horizontal input-output model and the achievable results; iii) to reveal and quantify the 'Recreationals' valuable hidden-clients and thus the indirect impact on their evolution in a resource-based view (R-BV) framework. In a forthcoming research, the hidden-clients characteristics of rarity, non-inimitability and non-substitutability will be examined.

\section{Basic R-BV concepts ${ }^{12}$}

$\underline{\text { Resource of the firms }}$

In the R-BV, the resource concept includes a large set of factors that enable that firm to conceive and implement its strategies under company control getting an increase in its efficiency and effectiveness (Daft, 2009). Furthermore, the R-BV in the context of long-term competitive strategies focuses its attention on productivity issue. The informal relationship between the firm and its environment and the role of organizational capital resources considered to be able to over perform firm's resource (Tomer, 1987). This research is engendered to reveal advancement in the light of the aforementioned concepts.

Competitive advantage vs. sustained competitive advantage

According to the traditional management approach, the company has a competitive advantage when reaching 'systematically above the average returns' (Shoemaker, 1990, p. 1179). This approach is inclusive of the concepts of resource and higher return to scale. The R-BV explores the role of resources. Resources diversification and stability are of main importance.

Following the R-BV, implementing a value creation strategy, not simultaneously being implemented by any current or potential competitors, the company has a sustained competitive advantage conditioned that other firms are unable to duplicate the benefits of this strategy (Barney, 1991). In this study, the usable and valuable resources may defend the enterprise competitive advantage and promote the territorial integration.

\section{Hidden-client as a resource}

Through a previous empirical study, sale trade contacts within intermediate market (ITC) were defined as the organizational B2B capital resource measured by sale market value of the firm in its value chain. However, this concept does not separate direct and indirect sales. In general terms, the R-BV emphasizes the role of efficiency and effectiveness in exploiting resources (Barney, 1991,

\footnotetext{
${ }^{12}$ This section is due mainly to Droli.
} 
p.101). This view is also inclusive and indicates how the continuous research of resources affecting the firm competitive advantage falls within management activities. Based on these theoretical assumptions, the authors clearly devised a new concept of hidden-clients or 'ghost-clients' as the portion of inter-firm trade contacts stemming from indirect customers of an industry or company. It is believed that, this definition is suitable for the purposes of this research. The R$\mathrm{BV}$ indicates that '... in order to know whether a firm's returns are above the average, an average must be calculated' (Barney, 2001, p. 47). Thereafter, the study presents input-output model contribution to that operationalization of the 'asymmetries in the competition for new resources' (Wernerfelt, 2011). Hiddenclients may create informative and communicational asymmetries.

\section{Methodology: the horizontal supply-driven or 'mirror model'13}

The supply-driven model is concerned with the denominated forward linkages and it uses the market share matrix $B$ and its inverse $[I-B]^{-1}$ instead of using the vertical coefficients of the traditional Leontief demand-driven model. It is remarked that the latter matrix is also denoted $[I-Q]^{-1}$ and called Ghosh's inverse matrix (Ghosh, 1958, pp. 58-64). Direct horizontal (or distributional) coefficient matrix is called 'intermediate use' matrix. It expresses the ratio between the sales of one branch to any branch and the total deliveries of products of the same branch in the economic system (Chang, 1994, p. 91). Therefore, $[I-B]^{-1}$ allows decomposition of the total branch products use in its direct and indirect content of primary costs and imports. In addition to that it permits the measurement of the direct and indirect contribution that these primary inputs give to total uses. Given a change in primary inputs, the direct and indirect impacts on domestic output can be determined. Sums by rows of horizontal inverse are supply multipliers, representing the total output change in the entire economy given by a unit change in primary inputs (Chen, Rose, 1986, p. 3). Such sum by rows of Ghosh's inverse are used to define downstream or sale linkages. This study considers only sale intermediate market trade contacts with a specific threshold value $(1 / 2 n)$ where $n$ is the number of branches (59). Following Ghosh, the supply-driven model should consider forward causal relations which take into account the economic rationale of the production process, from primary inputs to final goods (Ghosh, 1958) ${ }^{\mathrm{i}}$.

Supply-driven is also named mirror model since it implies the inversion of the causal flow with respect to more classical demand-driven model. Actually, the vertical model emphasizes the hierarchy of upstream flows (input purchases), while the horizontal model focuses itself on the hierarchy of downstream flows (intermediate sales).

\footnotetext{
${ }^{13}$ This section is due mainly to Chang and Iseppi. For a complete model version see (Droli et al., 2013).
} 


\section{The database and Recreational field of study ${ }^{14}$}

In this research, the horizontal model is applied in order to identify the structural relationships concerning the sale intermediate trade contacts (B2B) and to compare them among EU countries. For this purpose has been used a complete set of macro-level data including the intersectoral symmetric (59x59) inputoutput tables 2005 (NACE-Rev. 1 series) of whose countries which supplied them up to 2012 to EUROSTAT. Those domestic tables comprise 23 matrixes at basic prices, one for each country. Elaborations focused on 'Recreational, cultural and sporting activities' branch (Eurostat code no. 92) comprising 7 activity subsectors: 1) Motion picture and video; 2) Radio and television; 3) Other entertainment; 4) News agency; 5) Library, archives, museums and other cultural acts; 6) Sporting; 7) Other recreational as Gambling and betting.

\section{Discussion on main findings ${ }^{15}$}

According to Combs, et al. (2012) and Amit, Shoemaker (1993), the heterogeneity of the environment, in which the firms operate, is an important element because it can affect the way in which resources are used and can be in turn influenced.

Recreational valuable inter-firm sales in EU-27 countries economy

In the EU-27, the value of interfirm sales increases from $€ 7.95$ trillion (2000) to $€ 11$ trillion (2007) at a $4.76 \%$ compound annual growth rate, while that of 'Recreationals' augment from $€ 104.8$ billion to $€ 127.8$ billion in the same period, but only at a $2.89 \%$ compound annual growth rate. Thus, the alignment with the European market growth rate may represent a difficult challenge that could be converted to real innovation opportunity for 'Recreationals'.

In Euro Area-17 countries, the same intermediate sales represent a value of $€ 7.7$ trillion, in the period 2000-2007, its compound annual growth rate of increase was $4.67 \%$, a bit lower than that accounted for the EU-27 countries (2007). On the other hand, the market ITC value from the sales side, achieved by 'Recreationals' in 2007 amounted to $€ 90.4$ billion with an annual growth rate of $3.6 \%$ for the period 2000-2007, evidently and positively higher than that recorded for EU-27 countries. It follows that the above mentioned challenges could be overcome for 'Recreationals' operating in that area provided that the sharp instruments are obtainable.

However, performing this analysis has been limited because country tables are unavailable to $23 \mathrm{EU}$ countries, constituting the bulk of the ITC of the EU economic system. Nevertheless, for Latvia it is considered in the research with

\footnotetext{
${ }^{14}$ This section is due mainly to Droli and Iseppi.

${ }^{15}$ This section is due mainly to Droli and Chang.
} 
reference year 1995 since 2005 tables are not yet available. In fact, in the reference year (2005), business-to-business sales of 'Recreationals' amounted to $€ 110.85$ billion in the considered 23-EU countries and to $€ 80.27$ billion in the Euro Area-14 countries and its share reached $86.4 \%$ and $62.8 \%$ respectively of EU-27 countries ITC total ( $€ 127.5$ billion).

Revealing and quantifying Leisure and Entertainment valuable hidden-clients

Examining the domestic input-output coefficient matrix in the considered $23 \mathrm{EU}$ countries (2005), it is revealed that business-to-business direct and indirect valuable sales are 253, of which 141 indirect (55.7\%) and 112 direct (44.3\%). Investigating its distribution (Graph 1), the ranking of valuable direct and indirect client number puts in the first ten positions the following countries: IT, SE, DE, HU, BE, NL, PT, UK, DK, ES. Therefore, in the EU these most developed countries represent the main strategic markets for B2B 'Recreationals' since they are economically strong owing to the greatest capacity of activation of superior goods with an income demand elasticity $>1$. In these countries, it is revealed that indirect sale ITC hidden clients prevail in 8 out of 10, except in HU and the UK. While in the 23 examined EU countries, the total frequency of direct and indirect ITC achieves above normal value in Italy (27), but is very low in Slovakia (3). The study evidences the absent of hiddenclients in Latvia and Estonia. For the case of Latvia this could be attribueted to either lack of data or its no presence in the EU in 1995. This result proves the deep heterogeneity of benchmarks of Recreational in the selected $23 \mathrm{EU}$ countries in terms of client diversification portfolio.

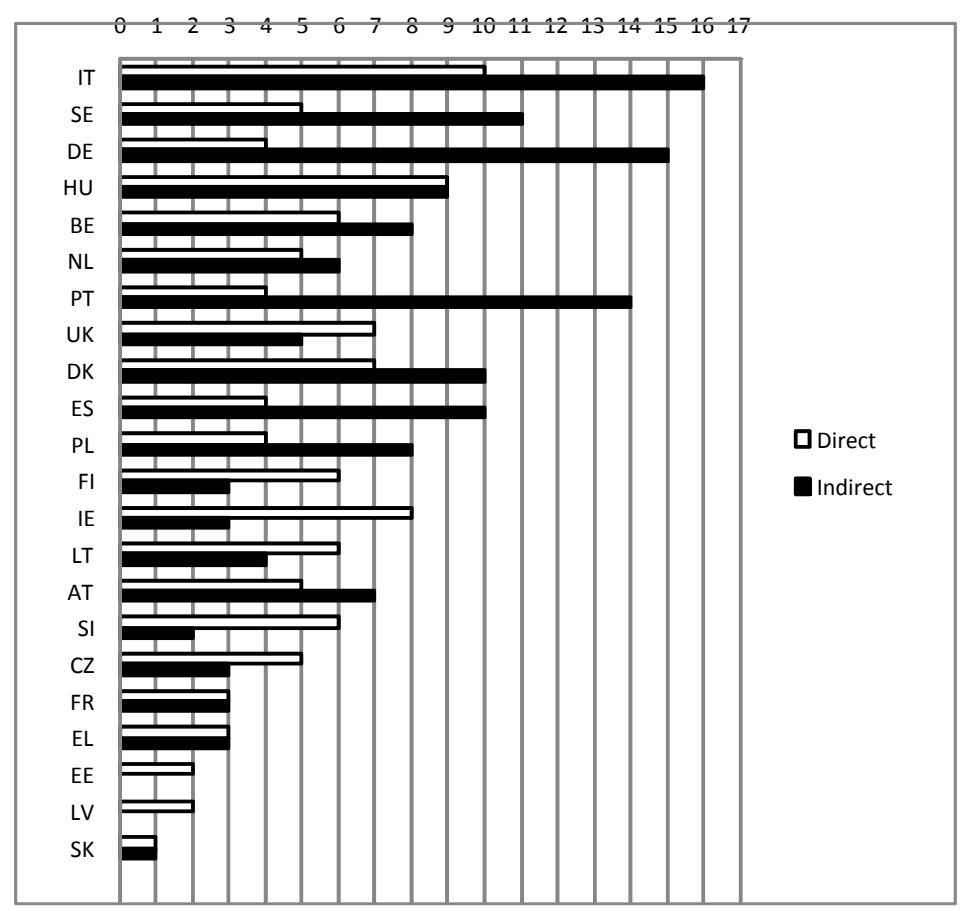

Fig. 1. EU-23 countries 2005 - Branch frequency of Recreational valuable B2B sale contacts. Source: Elaborations on Eurostat Input-Output Matrices. 
Concerning the distribution of valuable direct and indirect business-to-business sale contacts of Recreational branch among its clients, the main forward linkage frequency in the examined $23 \mathrm{EU}$ countries can be attributed to itself, but it is not the most frequent client of itself, due to statistical illusion. In effect, there is an excessive aggregation and heterogeneity of production subsectors that formed this industry. Its field of competence encompasses a lot of services that spread from both traditional and multimedial entertainment to cultural, sporting, gambling and betting activities. Self interchanges do not give raise to interindustry trade, but to intra-industry or horizontal trade. In most detailed tables, built on NACE Rev. 2 and ISIC last classifications, 'Recreationals' branch is subdivided into 3 different branches, so avoiding the above mentioned statistical illusion. Consequently, 'Recreationals' are not the main client of themselves. The other 9 industries which have the higher frequency of valuable direct and indirect purchases in the $23 \mathrm{EU}$ countries are as follows (Graph 2): Other business serv., Construction work, Public administration and defense serv., compulsory social security services, Wholesale trade and commission trade serv., Hotel and restaurant serv., Food products and beverages, Post and telecommunication serv., Printed matter and recorded media and Retail trade serv.; repair services of personal and household goods ${ }^{16}$. These industries are the main frequency clients of 'Recreationals'.

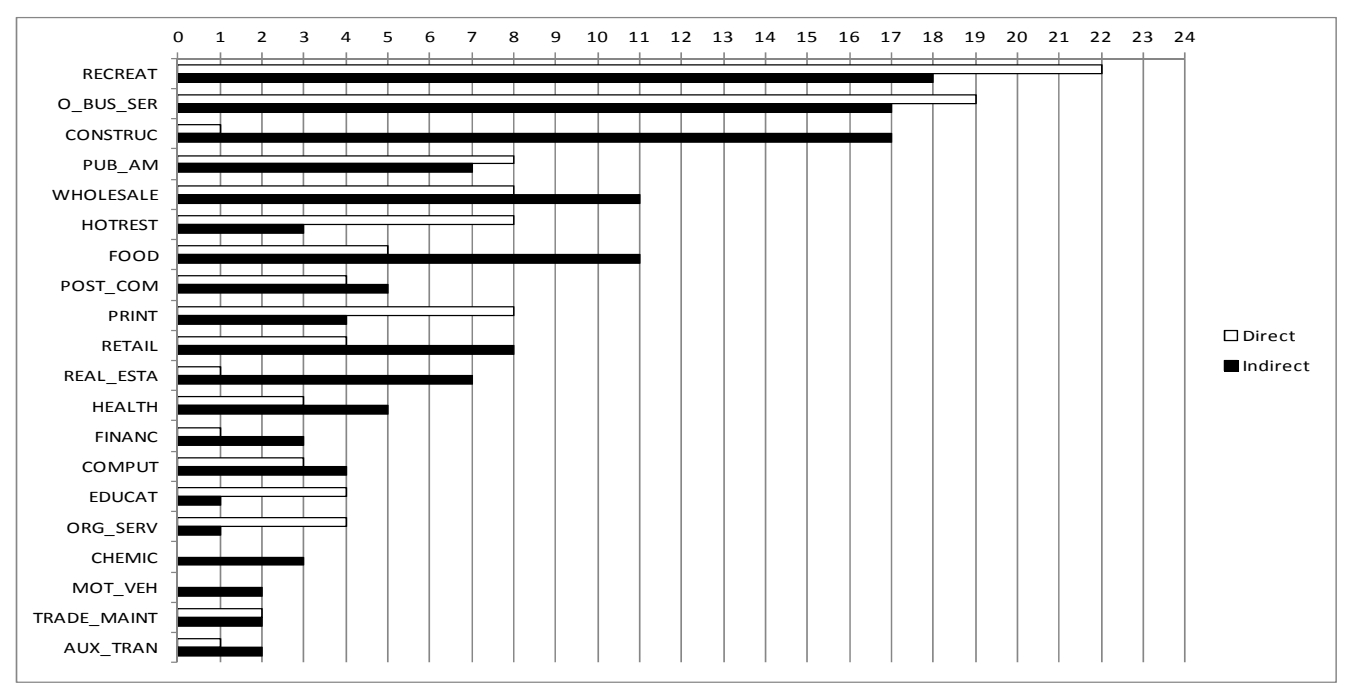

Fig.2. EU-23 countries 2005 - Country frequency of Recreational valuable B2B sale contacts. Source: Elaborations on Eurostat Input-Output Matrices.

Hereafter, the Recreational horizontal B2B frequency has been classified in three categories:

\footnotetext{
${ }^{16}$ O-BUS_SER, CONSTRUC, PUB_AM, WHOLESALE, HOTREST, FOOD, POST_COM, PRINT and
} RETAIL. 
a) sale valuable frequency to entirely hidden clients. The input-output method has been able to reveal them so reducing asymmetrical information which may cause market failure. Consequently, this result provides the basis to create a competitive advantage through 'unintentionally footholds' or small positions that happen to a firm within a market in which it does not yet compete (Upson et al., 2012). The most frequent in the $23 \mathrm{EU}$ countries totally hidden clients are Chemicals, chemical products and man-made fibres, Motor vehicles, trailers and semi-trailers, Machinery and equipment n.e.c., Land transport; transport via pipeline services, Products of agriculture, hunting and related services and Fabricated metal products ${ }^{17}$;

b) indirect more frequent than direct in the $23 \mathrm{EU}$ countries cover 10 positions among the most frequent 20 clients. Also in this case the method reveals the hidden sale linkage contributing to level the information asymmetry and thereby increasing market transparency and firm's efficiency. The following are the most frequent clients: Construction work, Wholesale trade and commission trade serv., Food products and beverages, Post and telecommunication serv., Retail trade serv., Real estate serv., Health and social work serv., Financial intermediation serv., Computer and related serv. and Auxiliary transport serv.; travel agency serv. ${ }^{18}$ among which are included the most frequent indirect sale client except Electrical energy, gas, steam and hot water ${ }^{19}$;

c) direct sales most frequent than indirect and exclusively most frequent direct clients are as follows:

c1) Recreational, cultural and sporting serv., Other business serv., Public administration and defense serv.; compulsory social security serv., Hotel and restaurant serv., Printed matter and recorded media ${ }^{20}$, already present among the above described most frequent direct and indirect clients;

c2) Education serv., Membership organization serv. n.e.c., Wearing apparel, furs, Radio, television and communication equipment and apparatus, Other business serv. ${ }^{21}$, low frequency clients in the 23 EU countries. The power of the input-output method is therefore evident considering that without the use of horizontal inverse matrix, it could not reveal the frequency of indirect relationships, so disregarding more than $50 \%$ of the phenomenon.

\footnotetext{
${ }^{17}$ CHEMIC, MOT_VEH, MACHIN, LAND_TRAN, AGRIC and FAB_MET.

${ }^{18}$ CONSTRUC, WHOLESALE, FOOD, POST_COM, RETAIL, REAL_ESTA, HEALTH, FINANC, COMPUT and AUX TRAN.

${ }^{19}$ ELET ENER.

${ }^{20}$ RECREAT, O BUS SER, PUB AM, HOTEL, PRINT.

${ }^{21}$ EDUCAT, ORG_SERV, WEARE, RADIO_TV, O_SERV.
} 


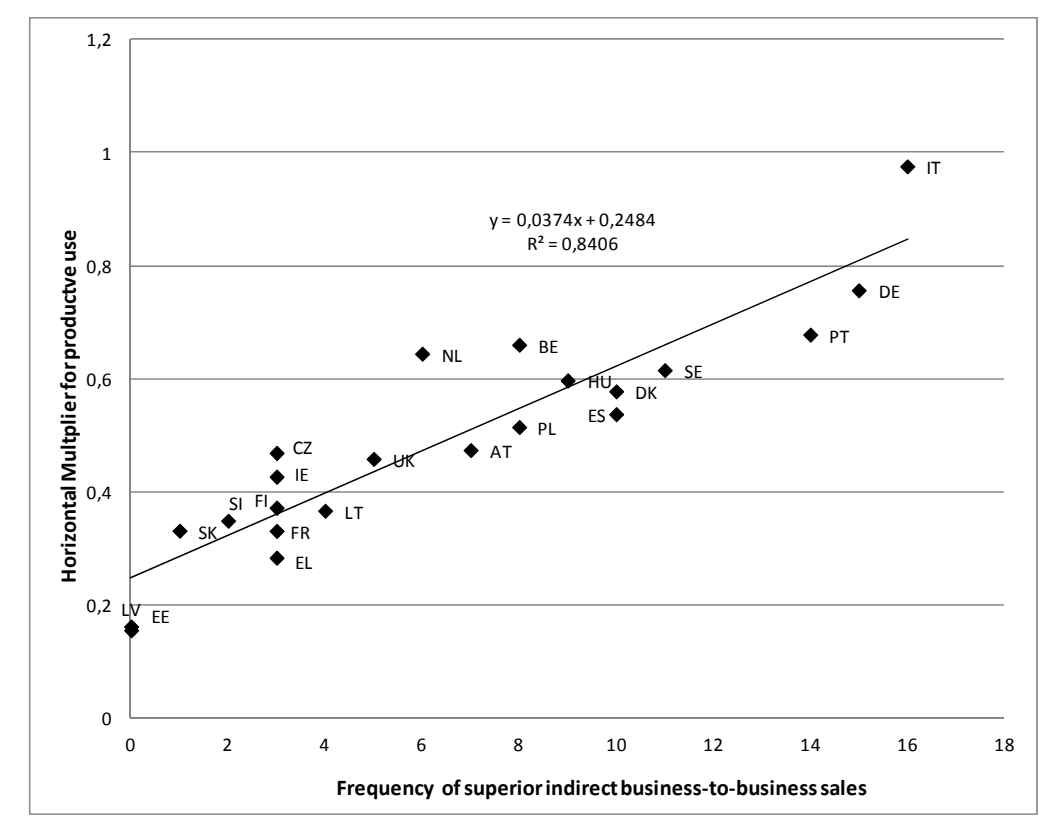

Fig.3. EU-23 countries 2005 - Recreational sale multiplier and frequency of valuable ITC Source: Elaborations on Eurostat Input-Output Matrices.

$\underline{\text { Relation between valuable indirect ITC and supply market sale multiplier for }}$ productive use

Graph. 3 represents the relationship between Recreational frequency of valuable hidden clients and its market sale multiplier for productive use. It is demonstrating a strong and direct two-way relationship $\left(\mathrm{R}^{2}=0.84\right)$ between interfirms valuable indirect trade contacts and the sale multiplier increases. When the number of valuable indirect ITC increases/decreases, the multiplier of the intermediate sales also increases/decreases, but less in proportion. This means that the diversification effects of valuable clients gradually become somehow less effective. The impact on sale multiplier of indirect forward link is evident, but, what is the impact of direct linkages? The further elaboration does not highlight any significant relationship between these two variables. The inference is that firms must focus on indirect relationships, more than on direct ones, as a flywheel to multiply their sales and to overcome the challenge of sustained competitive advantage.

\section{Conclusion $^{22}$}

The structure of the intermediate market is considered a benchmarking tool for the 'Recreationals' businesses to defend its their competitive advantage. The theoretical implications and studies adopting R-BV theory are sometimes subject to criticism (Priem, Butler, 2001). Especially when a firm management determines to face the difficulty of unknown important resource such as the

\footnotetext{
${ }^{22}$ This section is due mainly to Iseppi.
} 
'causal ambiguity' that characterizes some production processes (Lippman, Rumelt, 1982).

This study emphasizes the strong relationship between the valuable sale ITC frequency of the hidden-clients and the economic impact on 'Recreationals' businesses. This is an essential prerequisite to sensitize on the strategic role to be played in the competitive advantage defense of the firms.

Some scholars argue that the firm purchased resources cannot be considered as source of sustained competitive advantage just because acquirable (Dierickx, Cool, 1989). Precisely, this study uses input-output model in order to represent the very structure of the economic system that is by definition less subject to fluctuations than the final market supra-structure.

Other scholars point out that some changes in firm external environment can reduce the competitive advantage created through the resources characterized by attributes required by the R-BV (Priem, Butler, 2001; Peteraf, 1993; Rumelt, 1984). This study proves that this resource (valuable B2B sale frequency) is associated with a stronger feedback driven from the rest of the economic system. This implies that this resource can be transformed coeteris paribus into a source of sustained competitive advantage, independently of business-to-business market share obtained.

Regarding the methodological implications, 'Recreationals' hidden-clients are very heterogeneous, but their high frequency conservation can be a challenge in the broader business-to-business market. Their revelation may facilitate the development of specific communication strategies aimed to reduce the information asymmetry on the business-to-business environment. Simultaneously, the frequency of activated above average ITC is positively correlated with sale multiplier. The management of the hidden-clients can also facilitate cooperative capability acquisition to set up public-private partnerships implementing traceable among firms strategic alliances (Hansen et al., 2000; Droli, 2007; 2012).

\section{Summary $^{23}$}

The Resource-based view theory emphasizes the role of efficiency and effectiveness in exploiting resources (Barney, 1991, p.101) whose continuous research affecting the firm competitive advantage. On this base, the authors devised a new concept of hidden or 'ghost' clients as the portion of sale inter-firm trade contacts stemming from indirect customers. Thereafter, the study presents input-output model contribution to that operationalization of the 'asymmetries in the competition for new resources' (Wernerfelt, 2011). Hidden-clients create informative and communicational asymmetries.

\footnotetext{
${ }^{23}$ This section is common to the Authors.
} 
Following Ghosh, the supply-driven or mirror model considers forward or sale causal relations which take into account the economic rationale of the production process, from primary inputs to final goods (Ghosh, 1958). In this research, the horizontal input-output model is applied in order to identify the structural relationships concerning the sale intermediate trade contacts (B2B) and to compare them among 23 EU countries. In the whole economy of EU-27 countries, inter-firm sales (2007) accounted for $€ 11$ trillion and increased in the 2000-2007 period at the compound annual growth rate of $4.76 \%$. The relative incidence of Leisure and entertainment activities on total EU economy has decreased, in the same period, from $1.32 \%$ to $1.16 \%$ because their compound annual growth rate $(2.89 \%)$ was below the average. Examining the domestic input-output coefficient matrix in EU-23 countries (2005) for which data are available in 2012, it is revealed that business-to-business valuable indirect or hidden sales exceed on the total the direct ones $(55.7 \%$ versus $44.3 \%)$. The relationship between the frequency of valuable hidden clients and the Recreational market sale multiplier for productive use is strong and direct. Actually, when the first increases, the second also increases, but less in proportion. This means that the diversification effects of valuable clients gradually become somehow less effective.

The impact on sale multiplier of indirect forward link is evident. But, what is the impact of direct linkages? The further elaboration does not highlight any significant relationship between these two variables. The inference is that firms must focus on revealing indirect relationships, more than on direct ones, as a tool to maintain their sales and to overcome the challenge of sustained competitive advantage.

\section{Acknowledgment}

The Authors greatly appreciated Livio C. Piccinini and Mohamed Yassin valuable comments and suggestions and Sandro Clocchiatti database preparation.

\section{Bibliography}

1. Amit, R.; \& Schoemaker, P. (1993). Strategic assets and organizational rent. Strategic Management Journal, 14, 33-46.

2. Barney, J. (1991). Firm Resources and Sustained Competitive Advantage. Journal of Management, (17)1, 99-120.

3. Barney, J. (2001). Is the Resource-Based “"view” a Useful Perspective for Strategic Management Research? Yes. The Academy of Management Review, 26(1), 41-56.

4. Chang, T.F.M. (1994). L'analisi della struttura del sistema agroalimentare. Sistema agroalimentare e mercati agricoli, (a cura di) Cesaretti GP, Mariani AC, Sodano V. Bologna: Il Mulino.

5. Chang, T. F. M.; \& Iseppi, L. (2011). Specialization versus Diversification in EU Economies: a Challenge for Agro-food? Transition Studies Review, 18(1), 16-37.

6. Chang, T. F. M.; \& Iseppi, L. (2012). EU Agro-Food Chain and Vertical Integration Potentiality: a Strategy for Diversification? Transition Studies Review, 19(1), 107-130.

7. Chen, C.Y.; \& Rose, A. (1986). The Joint Stability of Input-Output Production and Allocation Coefficients. Research Paper 8617. National Cheng Kung University.

8. Combs, J.G.; \& Ketchen, J.J.; \& Ireland, R.; \& Webb, J.W. (2011). The role of resource flexibility in leveraging resource. Journal of Management Studies, 48(5), 1098-1125. 
9. Daft, R.L. (2009). Organization theory and design, Thomson Learning, Mason.

10. Droli, M. (2007). Partnering turistico. L'impostazione, la creazione, l'organizzazione ed il rinforzo continuo di una partnership strategica di successo. Collana Ambiente e Territorio. Udine: FORUM.

11. Droli, M. (2012). Vantaggio co-marketing. Mercati difficili, lavoro di squadra e rilancio dell'Italian Style. Collana Scienze economiche. Padova: Edizioni universitarie CLEUP.

12. Droli, M.; \& Chang, T.F.M.; \& Iseppi, L.; \& Piccinini, L.C. (2013). Managing Trade Contacts in HotRest Intermediate Markets: a Resource-based View Analysis in EU Countries. Under review.

13. Eurostat (2012).

http://epp.eurostat.ec.europa.eu/portal/page/portal/esa95_supply_use_input_tables/data/w orkbooks.

14. Dierickx, I.; \& Cool, K. (1989). Asset stock accumulation and sustainability of competitive advantage. Management Science, 35, 1504-1511.

15. Ghosh, A. (1958). Input-Output Approach in an Allocation System. Economica, 25(97), 58-64.

16. Hansen, M. H.; \& Hoskisson, R.E.; \& Barney, J. B. (2000). Resolving the opportunism minimization-opportunity maximization paradox. Working paper, Fisher College of Business. Columbus: Ohio State University.

17. Lippman, S. A.; \& Rumelt, R.P. (1982). Uncertain inimitability: An analysis of interfirm differences in efficiency under competition. Bell Journal of Economics, 13, 418-438.

18. Peteraf, M. (1993). The cornerstones of competitive advantage: A resource-based view. Strategic Management Journal, 14, 179-191.

19. Priem, R.L.; \& Butler J.E. (2001). Is the Resource-Based "View" a Useful Perspective for Strategic Management Research?. The Academy of Management Review, 26(1), 22-40.

20. Rumelt, R. (1984). Towards a strategic theory of the firm. In R. Lamb (Ed.), Competitive strategic management, 556- 570. Englewood Cliffs, NJ: Prentice-Hall.

21. Tomer, J.F. (1987). Organizational capital: The path to higher productivity and wellbeing. New York: Praeger.

22. Schoemaker, P.J.H. (1990). Strategy, complexity and economic rent. Management Science, 36, 1178-1192.

23. Upson, J.K.; \& Ketchen, D.J.; \& Connelly, B.L.; \& Ranft, A.L. (2012). Competitor Analysis and Foothold Moves. Academy of Management Journal, 55, 93-110.

24. Wernerfelt, B. (2011). The use of resources in resource acquisition. Journal of Management, 37, 1369-1373.

\begin{tabular}{|r|l|}
\hline Maurizio Droli & Department of Civil Engineering and \\
& Architecture, \\
& University of Udine, Italy \\
& E-mail: maurizio.droli@uniud.it \\
\hline Ting Fa Margherita & Department of Civil Engineering and \\
Chang & Architecture, \\
& University of Udine, Italy \\
& E-mail: chang@uniud.it \\
\hline Luca Iseppi & Department of Civil Engineering and \\
& Architecture, \\
& University of Udine, Italy \\
& E-mail: luca.iseppi@uniud.it \\
\hline
\end{tabular}

